\title{
High-dose intravenous immunoglobulins as a therapeutic option in critical illness polyneuropathy accompanying SARS-CoV-2 infection: A case-based review of the literature (Review)
}

\author{
ADINA STOIAN $^{1}$, ZOLTAN BAJKO $^{2}$, SMARANDA MAIER $^{2}$, ROXANA ADRIANA CIOFLINC ${ }^{3}$, \\ BIANCA LIANA GRIGORESCU ${ }^{1}$, ANCA MOȚĂȚĂIANU ${ }^{2}$, LAURA BĂRCUȚEAN ${ }^{2}$, \\ RODICA BALAȘA ${ }^{2 *}$ and MIRCEA STOIAN ${ }^{4 *}$
}

\begin{abstract}
Departments of ${ }^{1}$ Pathophysiology and ${ }^{2}$ Neurology, 'George Emil Palade' University of Medicine, Pharmacy, Sciences and Technology; ${ }^{3} 1$ st Neurology Clinic, Mures County Clinical Emergency Hospital; ${ }^{4}$ Department of Anesthesiology and Intensive Therapy, 'George Emil Palade' University of Medicine, Pharmacy, Sciences and Technology, 540136 Targu Mures, Romania
\end{abstract}

Received June 25, 2021; Accepted July 27, 2021

DOI: $10.3892 /$ etm.2021.10616

\begin{abstract}
The still ongoing COVID-19 pandemic has exposed the medical community to a number of major challenges. A significant number of patients require admission to intensive care unit (ICU) services due to severe respiratory, thrombotic and septic complications and require long-term hospitalization. Neuromuscular weakness is a common complication in critically ill patients who are treated in ICUs and are mechanically ventilated. This complication is frequently caused by critical illness myopathy (CIM) or critical illness polyneuropathy (CIP) and leads to difficulty in weaning from the ventilator. It is thought to represent an important neurologic manifestation
\end{abstract}

of the systemic inflammatory response syndrome (SIRS). COVID-19 infection is known to trigger strong immune dysregulation, with an intense cytokine storm, as a result, the frequency of CIP is expected to be higher in this setting. The mainstay in the diagnosis of this entity beside the high level of clinical awareness is the electrophysiological examination that provides evidence of axonal motor and sensory polyneuropathy. The present article presents the case of a 54-year-old woman with severe COVID 19 infection who developed neuromuscular weakness, which turned out to be secondary to CIP and was treated successfully with a high dose of human intravenous
Correspondence to: Dr Zoltan Bajko, Department of Neurology, 'George Emil Palade' University of Medicine, Pharmacy, Sciences and Technology, 50 Gheorghe Marinescu Street, 540136 Targu Mures, Romania

E-mail: bzoltan2003@yahoo.com

*Contributed equally

Abbreviations: APACHE Score, acute physiology and chronic health evaluation score; ARDS, acute respiratory distress syndrome; $\mathrm{BE}$, base excess; $\mathrm{CD}^{+}$, cluster of differentiation $4 ; \mathrm{CD}^{+}$, cluster of differentiation 8; CIM, critical illness myopathy; CIP, critical illness polyneuropathy; CIPNM, critical illness polyneuropathy and myopathy; CK, creatine kinase; CMAP, compound motor action potential; COVID-19, corona virus disease 2019; COVID-CSS, COVID-19 related cytokine storm syndrome; CPAP, continuous positive airway pressure; CRIMYNE, Critical Illness Myopathy and/or Neuropathy; CRP, C-reactive protein; CSF, cerebrospinal fluid; CT scan, computerized tomography scan; CXCL10, C-X-C motif chemokine ligand 10; EMG, electromyography; E-selectin, endothelial selectin; $\mathrm{FiO}_{2}$, fractional inspired $\mathrm{O}_{2}$ concentration; GBS, Guillain-Barré syndrome; G-SCF, granulocyte-colony stimulating factor; GM-CSF, granulocyte-macrophage colony stimulating factor; H1N1, hemagglutinin type 1 and neuraminidase type 1; ICU, intensive care unit; ICUAW, intensive unit acquired weakness; INF-I, interferon type I; IFN-III, interferon type III;
IFN- $\gamma$, interferon- $\gamma ; \operatorname{Ig} \mathrm{A}$, immunoglobulin A; IgG,immunoglobulin $\mathrm{G}$; IgM, immunoglobulin M; IL-1, interleukin-1; IL-18, interleukin-18; IL-1 $\alpha$, interleukin-1 $\alpha$; IL-1 $\beta$, interleukin-1 $\beta$; IL-2, interleukin-2; IL-4, interleukin-4; IL-5, interleukin-5; IL-6, interleukin-6; IL-7, interleukin-7; IL-10, interleukin-10; IVIg, intravenous immunoglobulins; MCP-1, monocyte chemoattractant protein-1; MERS, Middle East Respiratory Syndrome; MIP-1A, macrophage inflammatory protein-1 $\alpha$; MRC, Medical Research Council; MRI, magnetic resonance imaging; MUAPs, motor unit action potentials; NCS, nerve conduction studies; NF- $\kappa \mathrm{B}$, nuclear factor $\kappa$-light-chain-enhancer of activated B cells; NK, natural killer; NO, nitric oxide; $\mathrm{PaCO}_{2}$, partial pressure of carbon dioxide; $\mathrm{PaO}_{2}$, partial pressure of oxygen; $\mathrm{pH}$, potential of hydrogen; PNS, peripheral nervous system; RECOVERY, randomized evaluation of COVID-19 therapy; RT-qPCR, real-time reverse transcription polymerase chain reaction; ROS, reactive oxygen species; SARS, severe acute respiratory syndrome; SARS-CoV-1, severe acute respiratory syndrome coronavirus 1; SARS-CoV-2, severe acute respiratory syndrome coronavirus 2; SIRS, systemic inflammatory response syndrome; SNAP, sensory nerve action potential; SOFA Score, the sequential organ failure assessment score; Th-17, T helper 17; TNF- $\alpha$, tumor necrosis factor $\alpha$; WHO, World Health Organization

Key words: intravenous immunoglobulins, critical illness polyneuropathy, SARS-CoV-2 infection, COVID-19, neurological complications 
immunoglobulins. Related to this case, we reviewed the relevant literature data regarding the epidemiology, pathophysiology and clinical features of this important complication and discussed also the treatment options and prognosis.

\section{Contents}
1. Introduction
2. Incidence
3. Diagnostic, clinical, and electrophysiological features of CIP and/or CIM
4. Risk factors
5. Pathophysiology
6. Treatment
7. Prognosis
8. Practical applicability of IVIg in the treatment of CIP: Case illustration
9. Discussion
10. Conclusions

\section{Introduction}

The ongoing pandemic of corona virus disease 2019 (COVID-19) declared by the World Health Organization (WHO) on March 11, 2020 (1) caused by the severe acute respiratory syndrome coronavirus 2 (SARS-CoV-2) has infected individuals worldwide (2) and has evolved in many cases to a critical life-threatening form due to immune dysregulated response with multiorgan failure and refractory hypoxemia $(3,4)$. Although COVID-19 mainly affects the lungs, causing varying degrees of respiratory symptoms, there are numerous clinical and pathological studies that support the idea that this virus has the ability to spread to extrapulmonary tissues leading to a wide spectrum of neurological involvement to multiorgan failure in critically ill patients (5-7).

Motor weakness and respiratory muscle inefficiency in critically ill patients with sepsis include a flaccid and symmetric paralysis that has been described since 1892 by Osler $(8,9)$ and has been attributed to increased catabolism associated with this condition (8). Later, Mertens considered them secondary to ischemic and metabolic lesions affecting peripheral nerves and muscles (10).

The term 'critical illness polyneuropathy' (CIP) was introduced in 1984 by Bolton et al who described electrophysiological changes and defined CIP as a distal axonal polyneuropathy that affects both motor and sensory fibers, with lesions considered secondary to the 'toxic effects of sepsis' (11-14).

In recent years, another notion has been defined; that of 'critical illness myopathy' (CIM), which seems to be secondary to both the toxic effects of sepsis and the use of corticosteroids and neuromuscular blocking agents in the intensive care unit (ICU) $(8,15)$.

Most often in critically ill patients, there is an overlap of CIP and CIM that frequently coexist, and it is still discussed as to whether they are separate entities or have a common pathophysiological mechanism. Their association has been called ‘critical illness polyneuropathy and myopathy' (CIPNM) (8).
The two pathologies cannot be distinguished only on the basis of symptoms and clinical signs and paraclinical investigations are needed $(8,16,17)$. The newest term to define this common complication of patients admitted to the ICU, irrespective of the cause of hospitalization, is 'intensive care unit acquired weakness' (ICUAW). This term has been used since the 1980s (18) and may consist of CIP, CIM, or a combination of both (19). ICUAW is characterized by acquired weakness that affects the limbs, respiratory muscles, diaphragm, and phrenic nerves, and increases the time period required for weaning patients from the ventilator $(16,19,20)$.

The percentage of patients hospitalized with COVID-19 who are admitted to the ICU due to severe acute respiratory syndrome (SARS) varies according to published data, from $8 \%$ in Spain (21) to $18 \%$ in the Wuhan region (22).

The objective of this review was to evaluate the possible efficacy of intravenous immunoglobulins (IVIg) in patients with a rare reported neurological complication in the context of the COVID-19 pandemic.

For the literature review we performed a database search in PubMed, Embase and CINAHL with the following key words: 'COVID-19', 'critical illness polyneuropathy', 'intravenous immunoglobulins'. The time frame that the studies covered was December 1, 2019 to March 1, 2021. We included only articles written in English, with available full-text. A total of 152 articles were analyzed and cited.

\section{Incidence}

The incidence of CIP and/or CIM in clinical evaluation varies from 25 to $33 \%$ in patients with a minimum of 4 days on mechanical ventilation, increasing up to $58 \%$ in electrophysiological evaluation (23-28) and up to $49-77 \%$ in patients treated in the ICU over 7 days (29-31). Other authors, such as Latronico and Bolton (32) and Bednarík et al (33) claim that more than one third of severely ill patients are affected by CIP $(32,33)$ and the percentage may increase up to $100 \%$ when multiple organ failure is superimposed (34). The incidence tends to correlate with the severity and duration of the underlying disease $(16,35)$.

\section{Diagnostic, clinical, and electrophysiological features of CIP and/or CIM}

The most important information for the diagnosis of CIP and/or CIM is provided by clinical patient evaluation, patient evolution and ICU admission, electromyography (EMG), serum creatine kinase level (CK), and sometimes even muscle biopsy $(16,20)$. If there is ongoing muscle necrosis, laboratory tests may indicate elevated CK level, but it must be correlated with other findings due to its low sensitivity $(16,20)$.

The main clinical feature of CIP and/or CIM is progressive muscular weakness, which is often attributed to sepsis rather than atrophy immobilization (8). The incidence of these conditions increases with the length of hospitalization in the ICU and is followed by difficulty in weaning the patient from the ventilator after ending sedation $(16,27,30,36,37)$. Patients can present with tetraplegia that is frequently flaccid, with diminished deep tendon reflexes, distal hypoaesthesia and pallhypesthesia, disproportionate muscle atrophy with the degree 
and length of immobilization being more likely attributed to sepsis-induced myopathy $(8,15,38,39)$. The muscles innervated by cranial nerves are generally spared. Ophthalmoplegia may occur in case of muscle damage in CIM, but a differential diagnosis with Guillain-Barré syndrome (GBS) should be considered in this case $(8,40,41)$.

EMG is considered an essential method for making a proper diagnosis. CIP is a sensory motor axonal polyneuropathy, a pattern dependent on nerve length characterized by low amplitude of compound motor action potential (CMAP) and sensory nerve action potential (SNAP), while distal latencies and conduction velocities are within normal limits $(8,42-44)$ and there is a normal response to repetitive nerve stimulation (20). One factor to pay attention to is that the amplitude of the collected potentials, especially the sensitive ones, can be artificially reduced due to the presence in the lower limbs of edema in critical patients, which causes the distance between the recording electrodes and the underlying nerves to increase. This explains why the changes present in the upper limbs are considered to be more conclusive (45-47). In addition, SNAP is an important differential diagnostic element (it is decreased in CIP but not modified in CIM) (8). Electromyographic examination may reveal fibrillation potentials and positive sharp waves suggestive of denervation or myonecrosis (8). In the case of denervation, these changes may occur in the second or third week $(35,43,48)$. In the case of myopathic disorders, motor unit action potentials (MUAPs) are short and with low amplitude. In the case of CIP with axonal injury, a reduced recruitment-interference pattern is characteristic and occurs while in myopathy recruitment of a large number of MUAPs is characteristic (8).

The cerebrospinal fluid (CSF) level may be normal at the onset of GBS but increases towards the end of the second week in over $90 \%$ of patients, while in the case of CIP it does not change $(20,49)$.

\section{Risk factors}

The etiology of ICUAW involves many factors and has not yet been fully elucidated (50). The main risk factors for the occurrence of CIP and/or CIM identified in clinical trials are: the presence of sepsis, multiorgan failure and a systemic inflammatory response syndrome(SIRS) (36,51-55), use of corticosteroids, neuromuscular blocking agents $(16,23-24,33,56)$, female sex (23), hyperglycemia (29-31), prolonged ICU stay $(29,57)$, and different interventions such as prolonged mechanical ventilation $(50,58)$.

\section{Pathophysiology}

In the presence of an increased level of inflammatory cytokines, there are alterations in the microcirculation of the peripheral nerves, with increased expression of endothelial selectin (E-selectin) in the vascular endothelium, leading to increased microvascular permeability, extravasation of activated leukocytes $(8,46)$, and leakage of neurotoxic substances in the endoneurium, with subsequent endoneurial edema, which induces hypoxia and energy depletion and finally leads to axonal degeneration $(8,59)$. Hypoalbuminemia and hyperglycemia further contribute to increased endoneurial edema $(16,29)$.
Weakness can be the result of muscle wasting due to preferential loss of myosin, muscle protein degradation, neuropathy, and dysregulated autophagy (50).

There is evidence of acquired channelopathies in CIP in animal models $(60,61)$ with electrical alteration due to ion channel dysfunction with consequences on cell depolarization and inexcitability $(8,32)$. Sodium channels seem to be involved, as shown by electrodiagnostic studies $(62,63)$. Altered depolarization of the peripheral nerve membrane is thus explained by sodium channelopathy, endoneurial edema, hyperkaliemia, and even hypoxia $(46,64,65)$.

Druschky et al demonstrated, in an in vitro study, serum neurotoxicity in 12 out of 16 patients that were diagnosed with CIP, and they suspected the existence of a low-molecularweight neurotoxic agent (66).

The earlier onset of neuropathy and myopathy in patients with SARS-CoV-2 infection compared with those with severe acute respiratory syndrome coronavirus 1 (SARS-CoV-1) raises the suspicion of an injury of peripheral nerves and skeletal muscles driven by the virus (67).

The immune mediators that are excessively produced during SARS-CoV-2 infection include interleukin (IL)- $1 \beta$, IL-2, IL-6, IL-7, IL-10, tumor necrosis factor- $\alpha$ (TNF- $\alpha$ ) and also granulocyte-colony stimulating factor (G-SCF), monocyte chemoattractant protein-1 (MCP-1), macrophage inflammatory protein-1 $\alpha$ (MIP-1A), and C-X-C motif chemokine ligand 10 (CXCL10) $(6,68,69)$. Some proinflammatory cytokines such as IL-1, IL-6, TNF- $\alpha$ induce weakness and muscle atrophy (70). IL-1 $\beta$, IL-6, TNF- $\alpha$ and CXCL10 may generate tissue damage and be involved in the pathophysiology of neurological complications, including the peripheral nervous system (PNS) in COVID-19 (67,71).

The characteristics of patients with COVID-19 include systemic inflammation, the presence of cytokine storm, increased production of nitric oxide (NO) and reactive oxygen species (ROS), prolonged sedation, steroid use, occasional superimposed sepsis, and predisposition to ICUAW onset (50,72-74). Increased level of circulating inflammatory markers that accompany systemic inflammation is associated with a significant decrease in muscle mass and strength (75) to which muscle loss is added due to anorexia in COVID-19 patients $(74,76,77)$.

The plasma levels of TNF- $\alpha$ are higher in patients that develop ICUAW compared with controls and tests in vitro, with TNF- $\alpha$ added to cultured myotubes showing a reduction in myotube diameter and a decrease in muscle protein content $(78,79)$. Another cytokine that is highly elevated in the plasma of COVID-19 patients and is proven to drive muscle atrophy in animal models is IL-1 (80), and IL-1 blockade is correlated with survival benefits in humans with sepsis (81). IL- $1 \beta$ and TNF- $\alpha$ stimulate the production of IL- 6 , and blood levels of IL-6 are correlated with severity of the disease and mortality due to hyperinflammation driven by viral infection in COVID-19 patients (82-84). Based on these data, tocilizumab, which is an IL-6 receptor blocker, is currently used to treat pneumonia in COVID-19 patients with elevated IL-6 levels (85). Corticosteroids produce the inhibition of nuclear

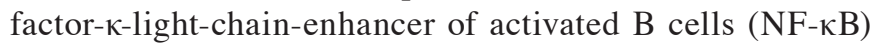
signaling, which inhibits among others the synthesis of IL-1 and IL-6 genes $(86,87)$, but the use of corticosteroids is somehow 
controversial because in critically ill patients with bacterial infections it is associated with increased mortality (88) and may induce myopathy in the case of prolonged use (89).

In addition to dysregulated immune response, there is a depletion in the blood of severely affected COVID-19 patients of immune cell subtypes including cluster of differentiation (CD) $4^{+}$and $\mathrm{CD}^{+}$, $\mathrm{T}$ lymphocytes, natural killer (NK) cells, dendritic cells and monocytes, which may be attracted to the sites of SARS-CoV-2 infection $(67,90)$. In addition, the remaining lymphocytes present functional exhaustion indicating, in fact, a state of immunosuppression similar to that in sepsis $(91,92)$. Direct effect driven by the virus with infection of nerve cells is also proposed to play a role in CIP (67) together with immune-mediated neurotoxicity $(67,73)$.

Patients with COVID-19 neuropathy or myopathy present increased levels of acute phase reactants and neutrophils (93). Other causes contributing to neuropathic and myopathic damage include thrombotic, ischemic, and vascular alterations produced by SARS-CoV-2 infection (67).

\section{Treatment}

Various prevention and prophylaxis measures to prevent the occurrence of ICUAW have been proposed, because to date, no specific therapy exists (20). These measures include the treatment of the underlying disease, sepsis, multiorgan failure and electrolyte and metabolic imbalances with aggressive control of hyperglycemia (20). Other therapeutic measures include rehabilitation programs, nutritional supplementation, and anti-oxidant therapy $(12,94)$.

Intensive insulin therapy has been shown to reduce the incidence of CIP and/or CIM from 51 to $39 \%$ in ICU medical patients, but great care must be taken to avoid hypoglycemia $(8,30,31,36)$.

The clinical efficacy of existing therapeutic strategies in COVID-19 is still uncertain, and there are many clinical attempts that have focused on immunomodulation and inflammatory cytokine neutralization.

Remdesivir is an antiviral drug which was proven in preclinical trials to block SARS-CoV-2 replication (95) but there are still no data on its benefits for neurological complications (67).

Tocilizumab is a monoclonal antibody targeted against IL-6 that acts by reducing cytokine production. It is used to reduce the inflammatory manifestations that accompany SARS-CoV-2 infection (96), but little controversial data exists about its effect on associated neurotoxicity (97), and recent studies have shown the beneficial effect of granulocyte-macrophage colony stimulating factor (GM-CSF) blockade with mavrilimumab, including neurological complications (98).

Corticosteroids and neuromuscular blocking agents should be administered with caution $(15,20)$. Short courses of steroids such as dexamethasone seem to provide benefits in the management of immune-mediated neurotoxicity, but with close follow-up of the patient due to the potential for induced immunosuppression (99).

IVIg is a blood product containing polyclonal immunoglobulin $\gamma(\mathrm{IgG})$ and smaller quantities of immunoglobulin A ( $\operatorname{Ig} \mathrm{A})$ and $\operatorname{IgM}$ and is obtained from a pool of plasma from many healthy donors. It is being used to treat many autoimmune disorders due to its capacity to modulate inflammatory response (2) through the reduction of the activation of self-reactive $\mathrm{T}$ cells and the production of inflammatory cytokines such as IL-4, IL-5, IL-6 and IFN- $\gamma$ exerting in this way an anti-inflammatory effect (100). The administration of IVIg in patients with Middle East Respiratory Syndrome (MERS) and severe acute respiratory syndrome (SARS) was reported to be correlated with a positive outcome (101-103). In COVID-19 patients, there is an overwhelming immune response which is thought to be modulated by the administration of IVIg $(2,4,6)$.

IVIg administration in CIP is still being debated without a consensus. Brunner et al published a randomized-controlled, double-blind study regarding the effect of early treatment with IgM-enriched IVIg in CIP. The study included 38 critically ill patients, 19 received IVIg and the rest received $1 \%$ human albumin solution for 3 days. Their results were not consistent with a positive effect of IVIg on the length of hospitalization or on the mortality of critically ill patients, but the duration of treatment was only 3 days (104). Mohr et al suggest that early administration of IVIg may prevent or help ameliorate CIP in patients with gram-negative sepsis admitted to the ICU (105), but this statement is not supported by large randomized-controlled studies (20), although it could make sense through the neutralizing effect of proinflammatory cytokines (100).

The neurotoxic effect of SARS-CoV-2 infection can be counteracted by the control and symptomatic treatment of fever, hypertension, and hyperglycemia (67).

\section{Prognosis}

The prognosis of CIM seems to be more favorable compared to CIP (106), while ICUAW is correlated with a sustained disability in the long term (50).

CIP and CIM are associated with an increased mortality rate and increased length of hospital stay in the ICU $(8,107)$. The CRIMYNE study (Critical Illness Myopathy and/or Neuropathy) suggests that the prognosis of CIP is more severe than CIM; after 1 year only 1 patient out of 4 recovered from CIP, while 5 out of 6 patients diagnosed with CIM fully recovered in 6 months (64), and the effects of CIP are more persistent over time $(28,64,108,109)$. CIP cases with unrecordable CMAP have a poor prognosis at 5 years with severe sequelae, such as tetraparesis or paraparesis $(8,110,111)$.

Functional outcomes vary, with some patients experiencing persistent weakness while others recovering fully to a previous status before ICU admission. For those with functional deficits, quality of life decreases, and the unemployment rates increase $(50,106,112)$. Long-term studies show that ICUAW has a worse evolution in elderly patients (over 65 years of age) (113).

\section{Practical applicability of IVIg in the treatment of CIP: Case illustration}

A 54-year-old woman was admitted in the Pneumology ward on August 26, 2020 having a sore throat, fever with the highest temperature at $38.4^{\circ} \mathrm{C}$, persistent non-productive cough, 
dyspnoea with peripheral oxygen saturation of $90 \%$ measured by pulse oximeter when breathing ambient air, and myalgia of 5-day duration. The nasopharyngeal swab test was positive for SARS-CoV-2 by real-time reverse transcription polymerase chain reaction (RT-qPCR) assay and the chest CT scan indicated bilateral subpleural and in the upper lobes ground glass opacities and infiltrations consistent with a moderate to severe form of pneumonia. She had second degree obesity and a medical history of hypertension that was well controlled with treatment.

On admission, laboratory tests revealed lymphocytopenia with a lymphocyte count of $0.81(1.2-3.4) \times 10^{9} / 1$, increased ferritin level 1,970 (13-150) $\mathrm{ng} / \mathrm{ml}$ and her blood sugar was $300 \mathrm{mg} / \mathrm{dl}$. She was not previously diagnosed with diabetes mellitus. She began treatment with lopinavir/ritonavir, dexamethasone, cefuroxime and insulin, but after 6 days following admission, her respiratory function worsened, the peripheral oxygen saturation decreased to $86 \%$ on the oxygen mask and she was transferred to the ICU. At admission in the ICU, the acid-base balance revealed metabolic acidosis with $\mathrm{pH} 7.12$, partial pressure of oxygen $\left(\mathrm{PaO}_{2}\right) 90 \mathrm{mmHg}$, partial pressure of carbon dioxide $\left(\mathrm{PaCO}_{2}\right) 40 \mathrm{mmHg}$ with base excess $(\mathrm{BE})$ $17 \mathrm{mmol}$, and bicarbonate $10 \mathrm{mEq} / \mathrm{l}$. The IL-6 level at admission in ICU was $600 \mathrm{ng} / \mathrm{ml}$ and the ferritin level was increased at $3,182 \mathrm{ng} / \mathrm{ml}$ with the sequential organ failure assessment (SOFA) Score of 11 and acute physiology and chronic health evaluation score (APACHE) Score of 25. During her ICU stay, her treatment was completed with supportive care and management of symptoms with correction of the acid base imbalance, enoxaparin sodium, azithromycin, intravenous methylprednisolone, tocilizumab ( $800 \mathrm{mg}$ total dose administered in 2 days), remdesivir $200 \mathrm{mg}$ in the first day then $100 \mathrm{mg}$ per day in the next 4 days and she was put on non-invasive ventilation with continuous positive airway pressure (CPAP) with a fractional inspired $\mathrm{O}_{2}$ concentration $\left(\mathrm{FiO}_{2}\right)$ of 0.7 . From the moment of ICU admission, a slight motor deficit with evolution towards aggravation first in the lower limbs, then later affecting the upper limbs was observed. Neurological examination was performed after 6 days and did not revealed changes in the cranial nerves but detected a flaccid tetraparesis of Medical Research Council (MRC) grade 4/5 in the upper limbs and grade $2 / 5$ in the lower limbs, diminished deep tendon reflexes in the upper limbs and abolished deep tendon reflexes in the lower limbs, with hypoaesthesia and hypopalesthesia with glove and stocking distribution. Her CK level was normal at admission and during hospitalization. Lumbar puncture was performed and SARS-CoV-2 or any other anomalies were not detected in the CSF of the patient and there was no albuminocytological dissociation. Magnetic resonance imaging (MRI) of the brain and whole spine was normal. Based on the clinical examination, the diagnosis of GBS was suspected and IVIg treatment was recommended by the neurologist. She was administered $0.4 \mathrm{mg} / \mathrm{kilogram}$ of body/day for 5 consecutive days beginning with the seventh day after admission in the ICU. In the meantime, a neurophysiologic investigation was also performed.

Neurophysiological protocol. Nerve conduction studies (NCS) in motor and sensory nerves of both the upper limbs (median and ulnar) and lower limbs (common peroneal, tibial, and sural nerves) were performed and concentric needle electromyography in proximal and distal muscle of the upper and lower limbs. Sensory nerves were stimulated and registered through antidromical stimulation. Repetitive nerve stimulation was performed on the right median nerve.

NCS revealed low amplitude of CMAP and SNAP, more expressed in the lower limbs, which was suggestive of axonal loss. Distal motor and sensory latencies, motor and sensory conduction velocities, and $\mathrm{F}$ waves latencies were performed and were within normal limits.

EMG was performed in distal and proximal muscles in upper limbs (first dorsal interosseous and deltoid) and lower limbs (tibialis anterior and vastus lateralis) revealing a spontaneous activity (fibrillations and positive sharp waves) in the distal muscles of the lower limbs characteristic of ongoing denervation.

The final diagnosis established after neurophysiological investigation was CIP. The diagnosis was supported by: i) clinical presentation with the appearance of limb weakness during the hospitalization; ii) normal level of CK; iii) CSF-lack of albuminocytological dissociation; iv) electrodiagnostic studies that showed axonal motor and sensory polyneuropathy with a SNAP amplitude lower than $80 \%$ in upper limbs and more decreased in the lower limbs; v) repetitive nerve stimulation without decremental response, in accordance with the criteria proposed by Latronico and Bolton (32); vi) nerve conduction studies (NCV) and EMG with the characteristics mentioned in the case description.

We present a case of CIP as a consequence of COVID-19 that was successfully treated with IVIg, which is, to the best of our knowledge, the first case with COVID-19 and CIP treated with IVIg.

After 16 days, the patient was transferred to the neurology ward with spontaneous breathing and intermittent oxygen supplementation on the mask with $\mathrm{FiO}_{2}$ of 0.4 and a peripheral oxygenation of $96 \%$. The motor deficit was improved to grade 4/5 (MRC) in the upper limbs and 3/5 MRC in the lower limbs. She was discharged and sent to a rehabilitation clinic. Two months later, the motor deficit completely disappeared in the upper limbs and was 4/5 MRC in the lower limbs, showing a significant improvement.

\section{Discussion}

Multiple neurological complications of COVID-19 have been described so far, with neurological sequelae caused by the direct potential harm of the virus to the nervous system, but also as a result of the systemic disease (19).

The neurotropism of human corona viruses was previously documented in the 2002-2003 SARS-CoV-1 outbreak. Neurological involvement, including neuromuscular manifestations, was described in 2002 when Tsai et al published an article (2004) in which they reported 4 patients with a probable diagnosis of CIP (114). Previous SARS experience has shown that organ dysfunction is caused by cytokine dysregulation (115). The virus causes SARS in 5-30\% of COVID-19 patients, affecting especially men in their fifth or sixth decades of life, leading them to require intensive life support interventions such as non-invasive ventilation or intubation and mechanical ventilation $(5-7,116)$. The fatal outcome in 
patients requiring mechanical ventilation is very high, close to $80 \%$ (116).

The concept of COVID-19 related cytokine storm syndrome (COVID-CSS) arose from the need to explain the dysregulated immune response that occurs in some patients with SARS-CoV-2 infection (6). This response has generated numerous clinical trials of immunomodulatory therapy or centered on cytokine inhibition (117). COVID-CSS is defined by experts as meeting the following criteria: activation of lymphocytes and macrophages, with increased production of cytokines and hypercytokinemia, which leads to systemic inflammation and multiple organ failure $(117,118)$. Patients with severe disease that require ICU admission have increased expression of inflammatory cytokines, especially IL-1 $\alpha$, IL-1 $\beta$, IL-6, IL-10, IL-18 and TNF- $\alpha$ with low interferon type I (INF-I) and IFN-III levels $(119,120)$, severe T-cell lymphopenia and low innate antiviral defense $(117,120)$. Other inflammatory markers, such as C-reactive protein (CRP) produced by hepatocytes in response to IL-6 stimulation, and ferritin produced as a result of increased macrophage activity, are increased (121). Treatment with tocilizumab, which acts by IL-6 blockade, can partially restore the immune defects $(117,122,123)$. The immunomodulatory effect of dexamethasone $6 \mathrm{mg}$ daily was demonstrated by the Randomised Evaluation of COVID-19 Therapy (RECOVERY) trial $(117,124)$.

The overwhelming immune response is characterized by a rapid progression to critical condition, with increased level of inflammatory factors and cytokines, and reduced peripheral lymphocyte count $(4,6,115)$.

Mortality in COVID-19 was reported between 2.7 and $3.4 \%$, leading to ICU admission in the case of severe impairment (125). It is very likely that neuromuscular damage in patients with COVID-19 and SARS-CoV-2 is more common and underdiagnosed, and many patients die without a neurophysiological diagnostic study.

During ICU stay, a significant proportion of critically ill patients being mechanically ventilated undergo muscular weakness and muscle atrophy $(50,126)$ due to an accumulation of causal factors which are difficult to define given the heterogeneity of ICU patients $(50,58,127)$.

CIP is an axonal polyneuropathy with a length dependent pattern involving both sensory and motor fibers that requires the confirmation of the clinically suspected diagnosis and electrophysiological studies to be performed in order to rule out GBS and CIM, along with EMG or even muscle biopsy $(128,129)$. Sometimes these two entities may coexist (19). The prognosis of CIM seems to be more favorable compared to CIP (106).

Cabañes-Martínez et al conducted a retrospective study that included 3,030 hospitalized patients with SARS-CoV-2 infection in Madrid between 31 March, 2020 and 18 May, 2020. A total of 225 COVID-19 patients were admitted to the ICU, and 12 of them were referred to the Neurophysiology Department for NCS and EMG (19) for the suspicion of ICUAW. The mean age of the 12 patients was 65 years (52-75 years) with a male predominance $(83.3 \%)$, with only 2 cases of female involvement $(16.7 \%)$. After neurophysiological examination, and in some cases muscle biopsy, they found 7 cases with CIM and 4 cases with CIP without any of these patients showing signs of both myopathy and neuropathy (19). The duration between ICU admission and the performance of the neurophysiological examination was between 12 and 49 days, with an average of 24 days. Of the 12 patients, 7 survived and were discharged, and 5 died (19). In the Cabañes-Martínez study, the laboratory tests performed presented elevated creatine kinase (CK) levels, lymphopenia, and elevated D-dimers (19).

When muscle weakness is evident on clinical examination, nerve conduction studies and EMG are performed to diagnose the presence of CIP, CIM or combined critical illness neuromyopathy $(50,126,130-132)$. The overlap of the two pathologies often makes the diagnosis difficult (50).

The occurrence of CIP and/or CIM associated with COVID-19 must be distinguished from GBS that can also be driven by the SARS-CoV-2 infection $(67,129,133)$.

Our patient suffered from a severe form of acute respiratory distress syndrome, which was caused by SARS-CoV-2, and she had a prolonged ICU stay (16 days) with generalized muscular weakness. We present the case of CIP as a consequence of COVID-19 which is to our knowledge the first case reported to be treated with IVIg resulting in a good outcome. Our patient was not diagnosed with a preexistent neuromuscular disorder.

We found in our patient decreased amplitude of CMAP and SNAP with normal duration, normal conduction speeds, and distal latencies. The changes were more evident in the lower limbs. Needle EMG showed the presence of mild spontaneous activity in distal but not in proximal muscles of the lower limbs with normal MUAPs. F-wave latencies were in normal limits, therefore the patient was diagnosed with sensory motor axonal neuropathy. CK blood level was also within normal limits.

Although EMG did not show myopathic changes, and the CK level was within normal limits, a certain degree of muscular involvement is difficult to be completely ruled out without performing a muscle biopsy (19). The CK level increases when there is muscle destruction, but the level fluctuates during the disease (134-136).

Being a new disease, with doctors lacking experience and effective treatment options (137) in the management of these patients, with no consensus on approved treatment protocols at the outbreak of the disease, off-label and empirical treatments were frequently administered in COVID-19 and its complications, including IVIg (115). In October 2020, a 60 -year-old patient's case was published with a medical history of hypertension and diabetes mellitus, with myocarditis secondary to SARS-CoV-2 infection, and he was treated early with IVIg that appears to have contributed to the rapid recovery of the patient (138).

IVIg is a blood product with antibacterial and antiviral broad-spectrum activity that has been used before in the treatment of autoimmune and inflammatory disease such as autoimmune thrombocytopenic purpura, GBS, myasthenia gravis or severe bacterial and viral infections for more than 30 years $(129,133,139-142)$. In the previous outburst of SARS and MERS, IVIg was well-tolerated and showed clinical benefits. Due to its immune modulation, high doses of IVIg could be considered a promising therapeutic strategy for selected cases (101-103,115). Previous studies regarding the use of IVIg in severe hemagglutinin type 1 and neuraminidase type 1 (H1N1) infections proved the treatment efficacy in reducing the viral load and mortality (143), but currently, data to support the effectiveness of this treatment in COVID-19 patients are controversial $(115,144,145)$. Tabarsi et al conducted a 
randomized controlled study in which they proved that faster administration of IVIg was correlated with a shorter length of hospitalization in the ICU (137). However, they could not confirm a favorable effect on mortality and the need for mechanical ventilation or improvement in the chest CT and emphasize the need for this treatment before the development of systemic damage $(115,137)$.

Shao et al published the first study that evaluated the efficiency of IVIg in critical COVID-19 patients and showed that early administration (before 7 days after admission) and high dose (more than $15 \mathrm{~g}$ per day) had a significant reduction in 60-day mortality in critical patients, and improved the prognosis and reported the decrease of CRP and IL-6 plasma levels (3).

Among the first reports of IVIg efficacy in the treatment of deteriorating patients with COVID-19 is that of Cao et al who published a series of 3 cases of severe pneumonia induced by SARS-CoV-2 who were successfully treated with high doses at the beginning of clinical deterioration. All 3 patients survived and were discharged (115). Reynaga et al from Spain, published a study consisting of a series of 5 patients, 3 males and 2 women between 24 and 80 years of age who received a 5-day course of IVIg $400 \mathrm{mg} / \mathrm{kg} /$ day for a medium risk of acute respiratory distress syndrome (ARDS). After IVIg infusion, their respiratory condition evolved favorably with resolution of pulmonary infiltrates on chest radiography and progressive increases in lymphocyte count in the first 2 weeks after treatment, and normalization of inflammatory biomarkers (CRP, fibrinogen, IL-6) by day 14 (146). IVIg, due to their immunomodulator properties, have the ability to form immunocomplexes with pathogen antigens with their removal from circulation, neutralize inflammatory cytokines, reduce the activation of complement, promote the regeneration of regulatory $\mathrm{T}$ cell and $\mathrm{B}$ cell lymphocytes, and reduce the pro-inflammatory $\mathrm{T}$ helper 17 cell (Th-17) cell activation (146-148). These data suggest the ability of IVIg to block the inflammatory cascade and prevent disease progression by improving the outcome of COVID-19 patients (115).

IVIg have not been shown to be effective compared to placebos in a recent randomized control trial that included patients with influenza A and B infection (149). But according to Xie et al IVIg treatment significantly reduced the mortality when administered early after admission in ICU in patients with COVID-19 infection before permanent tissue damage (145).

Another multicenter retrospective cohort study that included 325 COVID-19 patients which received IVIg, showed that if at first there were no significant differences at the primary analysis after adjustments based on disease severity, the results demonstrated a significant reduction on 60-day mortality rates, and good results were correlated with early administration (less than 7 days after hospital admission) (3).

Gharebaghi et al conducted a randomized placebocontrolled double-blind study regarding the use of IVIg in patients with severe forms of COVID-19, which provides evidence that the outcome is improved with the administration of IVIg, and they suggested that this treatment is more effective in the case of severe immune response and can reduce mortality in patients with aggressive COVID-19 pneumonia (2).

The timing of immunomodulatory therapy is extremely important. It should be administered at the beginning of clinical deterioration and before the onset of fatal immune-mediated injuries (115). Our patient showed no adverse effects upon IVIg administration, as in the data published by Cao et al (115).

The positive response in our case may also be due to combined antiviral therapy and IL-6 targeted immunotherapies, thus we cannot attribute the favorable evolution only to IVIg treatment, but it draws attention to the therapeutic potential of IVIg in such neurological complications, and the usefulness of their administration. Its effectiveness was likely to have been enhanced by the combined effect with other immunomodulatory therapies (137).

Additional studies focusing on dysregulated immune response and the complications resulting from its onset, including CIP, are needed. More studies are necessary to determine an algorithm of proper treatment in CIP accompanying acute respiratory distress syndrome from COVID-19.

Due to the pressure on the medical world to discover proper treatments for COVID-19 patients, and for the complications accompanying the disease, we decided to report our data and carry out a review of the medical literature regarding the effect of IVIg in regards to COVID-19 and CIP $(150,151)$.

Within the limits of our case, it would have been useful to perform a muscle biopsy. But the normal level of CK, the clinical characteristics, and the electromyographic appearance called for the diagnosis of CIP $(15,16,45)$. Muscle biopsy can be used additionally in difficult cases (20). Anti-gangliosides antibodies would have been helpful, together with NCS, in differentiating CIP from axonal GBS, but they were not available in our hospital $(35,129)$.

The evaluation of the beneficial effect of IVIg was based mainly on the follow-up of the clinical evolution, rather than viral load and inflammatory biomarker monitoring.

\section{Conclusions}

CIP is a common complication in the ICU, especially in patients with respiratory failure, organ dysfunction, SIRS, and sepsis. In the context of the COVID-19 pandemic, we can expect an increase in the number of reported cases and therapeutic strategies needing to be supplemented. Reporting such cases may be useful for the development of appropriate and complete therapeutic guidelines. The positive evolution of our patient suggests that IVIg could be a therapeutic alternative for such cases, however, further studies are needed.

\section{Acknowledgements}

Not applicable.

\section{Funding}

No funding was received.

\section{Availability of data and materials}

Not applicable.

\section{Authors' contributions}

AS designed the article. ZB, SM, RAC, BLG, LB, and AM collected the related articles and analyzed the literature data. 
$\mathrm{AS}, \mathrm{ZB}$, and SM collected the data on the presented case. AS and $\mathrm{ZB}$ wrote and edited the manuscript in light of the literature data. RB and MS critically revised the manuscript in light of the literature data. All authors have read and approved the final manuscript for publication.

\section{Ethics approval and consent to participate}

Inform consent was obtained from the patient for publication. Ethical approval was not necessary for the case report.

\section{Patient consent for publication}

Not applicable.

\section{Competing interests}

The authors declare that they have no competing interests.

\section{References}

1. GhebreyesusWD-GTA:WHODirector-General'sopeningremarks at the media briefing on COVID-19-11 March 2020 USA. World Health Organisation, 2020. Available from: https://www. who.int/director-general/speeches/detail/who-director-general-sopening-remarks-at-the-media-briefing-on-covid-19-11-march-2020 Accessed in February 15, 2021.

2. Gharebaghi N, Nejadrahim R, Mousavi SJ, Sadat-Ebrahimi SR and Hajizadeh R: The use of intravenous immunoglobulin gamma for the treatment of severe coronavirus disease 2019: A randomized placebo-controlled double-blind clinical trial. BMC Infect Dis 20: 786, 2020.

3. Shao Z, Feng Y, Zhong L, Xie Q, Lei M, Liu Z, Wang C, Ji J, Liu H, $\mathrm{Gu} \mathrm{Z}$, et al: Clinical efficacy of intravenous immunoglobulin therapy in critical ill patients with COVID-19: A multicenter retrospective cohort study. Clin Transl Immunology 9: e1192, 2020.

4. Zhu N, Zhang D, Wang W, Li X, Yang B, Song J, Zhao X, Huang B, Shi W, Lu R, et al: China novel coronavirus investigating and research team: A novel coronavirus from patients with pneumonia in China, 2019. N Engl J Med 382: 727-733, 2020.

5. Guan WJ, Ni ZY, Hu Y, Liang WH, Ou CQ, He JX, Liu L, Shan H, Lei CL, Hui DSC, et al: Clinical characteristics of coronavirus disease 2019 in China. N Engl J Med 382: 1708-1720, 2020.

6. Huang C, Wang Y, Li X, Ren L, Zhao J, Hu Y, Zhang L, Fan G, Xu J, Gu X, et al: Clinical features of patients infected with 2019 novel coronavirus in Wuhan, China. Lancet 395: 497-506, 2020.

7. Wang D, Hu B, Hu C, Zhu F, Liu X, Zhang J, Wang B, Xiang H, Cheng Z, Xiong Y, et al: Clinical characteristics of 138 hospitalized patients with 2019 novel coronavirus-infected pneumonia in Wuhan, China. JAMA 323: 1061-1069, 2020.

8. Zink W, Kollmar R and Schwab S: Critical illness polyneuropathy and myopathy in the intensive care unit. Nat Rev Neurol 5: 372-379, 2009.

9. Osler W: The Principles and Practice of Medicine, 1st edition, D. Appleton and Company, New York, 1892.

10. Mertens HG: Disseminated neuropathy following coma. On the differentation of so-called toxic polyneuropathy. Nervenarzt 32: 71-79, 1961 (In German).

11. Bolton CF, Gilbert JJ, Hahn AF and Sibbald WJ: Polyneuropathy in critically ill patients. J Neurol Neurosurg Psychiatry 47: 1223-1231, 1984.

12. Bolton CF, Laverty DA, Brown JD, Witt NJ, Hahn AF and Sibbald WJ: Critically ill polyneuropathy: Electrophysiological studies and differentiation from Guillain-Barré syndrome. J Neurol Neurosurg Psychiatry 49: 563-573, 1986.

13. Bolton CF: Sepsis and the systemic inflammatory response syndrome: Neuromuscular manifestations. Crit Care Med 24: 1408-1416, 1996.

14. Bolton CF: Neuromuscular manifestations of critical illness. Muscle Nerve 32: 140-163, 2005.

15. Friedrich O: Critical illness myopathy: Sepsis-mediated failure of the peripheral nervous system. Eur J Anaesthesiol Suppl 42: 73-82, 2008.
16. Hermans G, De Jonghe B, Bruyninckx F and Van den Berghe G: Clinical review: Critical illness polyneuropathy and myopathy. Crit Care 12: 238, 2008

17. Lacomis D and Campellone JV: Critical illness neuromyopathies. Adv Neurol 88: 325-335, 2002.

18. Bolton CF: The discovery of critical illness polyneuropathy: A memoir. Can J Neurol Sci 37: 431-438, 2010.

19. Cabañes-Martínez L, Villadóniga M, González-Rodríguez L, Araque L, Díaz-Cid A, Ruz-Caracuel I, Pian H, Sánchez-Alonso S, Fanjul S, Del Álamo M and Regidor I: Neuromuscular involvement in COVID-19 critically ill patients. Clin Neurophysiol 131: 2809-2816, 2020.

20. Zhou C, Wu L, Ni F, Ji W, Wu J and Zhang H: Critical illness polyneuropathy and myopathy: A systematic review. Neural Regen Res 9: 101-110, 2014.

21. Casas-Rojo JM, Antón-Santos JM, Millán-Núñez-Cortés J, Lumbreras-Bermejo C, Ramos-Rincón JM, Roy-Vallejo E, Artero-Mora A, Arnalich-Fernández F, García-Bruñén JM, Vargas-Núñez JA, et al: Clinical characteristics of patients hospitalized with COVID-19 in Spain: Results from the SEMI-COVID-19 Registry. Rev Clin Esp 220: 480-494, 2020 (In Spanish).

22. Epidemiology Working Group for NCIP Epidemic Response, Chinese center for disease control and prevention: The epidemiological characteristics of an outbreak of 2019 novel coronavirus diseases (COVID-19) in China. Zhonghua Liu Xing Bing Xue Za Zhi 41: 145-151, 2020 (In Chinese).

23. De Jonghe B, Sharshar T, Lefaucheur JP, Authier FJ, Durand-Zaleski I, Boussarsar M, Cerf C, Renaud E, Mesrati F, Carlet $\mathrm{J}$, et al: Paresis acquired in the intensive care unit: A prospective multicenter study. JAMA 288: 2859-2867, 2002.

24. de Letter MA, Schmitz PI, Visser LH, Verheul FA, Schellens RL, Op de Coul DA and van der Meché FG: Risk factors for the development of polyneuropathy and myopathy in critically ill patients. Crit Care Med 29: 2281-2286, 2001.

25. De Jonghe B, Bastuji-Garin S, Sharshar T, Outin H and Brochard L: Does ICU-acquired paresis lengthen weaning from mechanical ventilation? Intensive Care Med 30: 1117-1121, 2004.

26. Leijten FS, De Weerd AW, Poortvliet DC, De Ridder VA, Ulrich C and Harink-De Weerd JE: Critical illness polyneuropathy in multiple organ dysfunction syndrome and weaning from the ventilator. Intensive Care Med 22: 856-861, 1996.

27. Garnacho-Montero J, Amaya-Villar R, García-Garmendía JL, Madrazo-Osuna J and Ortiz-Leyba C: Effect of critical illness polyneuropathy on the withdrawal from mechanical ventilation and the length of stay in septic patients. Crit Care Med 33: 349-354, 2005.

28. Leijten FS, Harinck-de Weerd JE, Poortvliet DC and de Weerd AW: The role of polyneuropathy in motor convalescence after prolonged mechanical ventilation. JAMA 274: 1221-1225, 1995.

29. Van den Berghe G, Schoonheydt K, Becx P, Bruyninckx F and Wouters PJ: Insulin therapy protects the central and peripheral nervous system of intensive care patients. Neurology 64: 1348-1353, 2005.

30. Hermans G, Schrooten M, Van Damme P, Berends N, Bouckaert B, De Vooght W, Robberecht W and Van den Berghe G: Benefits of intensive insulin therapy on neuromuscular complications in routine daily critical care practice: A retrospective study. Crit Care 13: R5, 2009.

31. Hermans G, Wilmer A, Meersseman W, Milants I, Wouters PJ, Bobbaers H, Bruyninckx F and Van den Berghe G: Impact of intensive insulin therapy on neuromuscular complications and ventilator dependency in the medical intensive care unit. Am J Respir Crit Care Med 175: 480-489, 2007.

32. Latronico N and Bolton CF: Critical illness polyneuropathy and myopathy: A major cause of muscle weakness and paralysis. Lancet Neurol 10: 931-941, 2011.

33. Bednarík J, Vondracek P, Dusek L, Moravcova E and Cundrle I: Risk factors for critical illness polyneuromyopathy. J Neurol 252: 343-351, 2005.

34. Tennilä A, Salmi T, Pettilä V, Roine RO, Varpula T and Takkunen O: Early signs of critical illness polyneuropathy in ICU patients with systemic inflammatory response syndrome or sepsis. Intensive Care Med 26: 1360-1363, 2000.

35. Bercker S, Weber-Carstens S, Deja M, Grimm C, Wolf S, Behse F, Busch T, Falke KJ and Kaisers U: Critical illness polyneuropathy and myopathy in patients with acute respiratory distress syndrome. Crit Care Med 33: 711-715, 2005.

36. Hermans G, De Jonghe B, Bruyninckx F and Van den Berghe G: Interventions for preventing critical illness polyneuropathy and critical illness myopathy. Cochrane Database Syst Rev: Jan 30, 2009 (Epub ahead of print). doi: 10.1002/14651858.CD006832.pub3. 
37. De Jonghe B, Bastuji-Garin S, Durand MC, Malissin I, Rodrigues P, Cerf C, Outin H and Sharshar T; Groupe de Réflexion et d'Etude des Neuromyopathies en Réanimation: Respiratory weakness is associated with limb weakness and delayed weaning in critical illness. Crit Care Med 35: 2007-2015, 2007.

38. Eikermann M, Koch G, Gerwig M,Ochterbeck C, Beiderlinden M, Koeppen S, Neuhäuser M and Peters J: Muscle force and fatigue in patients with sepsis and multiorgan failure. Intensive Care Med 32: 251-259, 2006.

39. Zifko UA, Zipko HT and Bolton CF: Clinical and electrophysiological findings in critical illness polyneuropathy. J Neuro Sci 159: 186-193, 1998

40. Bird SJ: Diagnosis and management of critical illness polyneuropathy and critical illness myopathy. Curr Treat Options Neurol 9: 85-92, 2007.

41. van Mook WN and Hulsewé-Evers RP: Critical illness polyneuropathy. Curr Opin Crit Care 8: 302-310, 2002.

42. Latronico N, Fenzi F, Recupero D, Guarneri B, Tomelleri G, Tonin P, De Maria G, Antonini L, Rizzuto N and Candiani A: Critical illness myopathy and neuropathy. Lancet 347: 1579-1582, 1996.

43. Bednarík J, Lukas Z and Vondracek P: Critical illness polyneuromyopathy: The electrophysiological components of a complex entity. Intensive Care Med 29: 1505-1514, 2003.

44. Latronico N, Bertolini G, Guarneri B, Botteri M, Peli E, Andreoletti S, Bera P, Luciani D, Nardella A, Vittorielli E, et al: Simplified electrophysiological evaluation of peripheral nerves in critically ill patients: The Italian multi-centre CRIMYNE study. Crit Care 11: R11, 2007.

45. Dhand UK: Clinical approach to the weak patient in the intensive care unit. Respir Care 51: 1024-1041, 2006.

46. Z'Graggen WJ, Lin CS, Howard RS, Beale RJ and Bostock H: Nerve excitability changes in critical illness polyneuropathy. Brain 129: 2461-2470, 2006.

47. Z'Graggen WJ and Bostock H: Nerve membrane excitability testing. Eur J Anaesthesiol Suppl 42: 68-72, 2008

48. Cankayali I, Dogan YH, Solak I, Demirag K, Eris O, Demirgoren S and Moral AR: Neuromuscular deterioration in the early stage of sepsis in rats. Crit Care 11: R1, 2007.

49. van der Meché FG and van Doorn PA: Guillain-Barré syndrome and chronic inflammatory demyelinating polyneuropathy: Immune mechanisms and update on current therapies. Ann Neurol 37 (Suppl 1): S14-S31, 1995.

50. Lad H, Saumur TM, Herridge MS, Dos Santos CC, Mathur S, Batt J and Gilbert PM: Intensive care unit-acquired weakness: Not just another muscle atrophying condition. Int J Mol Sci 21: $7840,2020$.

51. Schweickert WD and Hall J: ICU-acquired weakness. Chest 131 1541-1549, 2007.

52. Young GB: Critical illness myopathy: Deeper insights. Crit Care Med 36: 1977, 2008

53. Nanas S, Kritikos K, Angelopoulos E, Siafaka A, Tsikriki S, Poriazi M, Kanaloupiti D, Kontogeorgi M, Pratikaki M, Zervakis D, et al: Predisposing factors for critical illness polyneuromyopathy in a multidisciplinary intensive care unit. Acta Neurol Scand 118: 175-181, 2008.

54. Visser LH: Critical illness polyneuropathy and myopathy: Clinical features, risk factors and prognosis. Eur J Neurol 13: 1203-1212, 2006.

55. Hough CL and Needham DM: The role of future longitudinal studies in ICU survivors: Understanding determinants and pathophysiology of weakness and neuromuscular dysfunction. Curr Opin Crit Care 13: 489-496, 2007.

56. Herridge MS, Cheung AM, Tansey CM, Matte-Martyn A, Diaz-Granados N, Al-Saidi F, Cooper AB, Guest CB, Mazer CD Mehta S, et al: Canadian critical care trials Group: One-year outcomes in survivors of the acute respiratory distress syndrome. N Engl J Med 348: 683-693, 2003.

57. Witt NJ, Zochodne DW, Bolton CF, Grand'Maison F, Wells G, Young GB and Sibbald WJ: Peripheral nerve function in sepsis and multiple organ failure. Chest 99: 176-184, 1991.

58. Yang $\mathrm{T}, \mathrm{Li} \mathrm{Z}$, Jiang $\mathrm{L}$, Wang $\mathrm{Y}$ and $\mathrm{Xi} \mathrm{X}$ : Risk factors for intensive care unit-acquired weakness: A systematic review and meta-analysis. Acta Neurol Scand 138: 104-114, 2018.

59. Fenzi F, Latronico N, Refatti N and Rizzuto N: Enhanced expression of E-selectin on the vascular endothelium of peripheral nerve in critically ill patients with neuromuscular disorders. Acta Neuropathol 106: 75-82,2003.

60. Lacomis D: Neuromuscular disorders in critically ill patients: Review and update. J Clin Neuromuscul Dis 12: 197-218, 2011.
61. Friedrich O, Hund E, Weber C, Hacke W and Fink RH: Critical illness myopathy serum fractions affect membrane excitability and intracellular calcium release in mammalian skeletal muscle. J Neurol 251: 53-65, 2004.

62. Rich MM and Pinter MJ: Crucial role of sodium channel fast inactivation in muscle fibre inexcitability in a rat model of critical illness myopathy. J Physiol 547: 555-566, 2003.

63. Haeseler G, Foadi N, Wiegand E, Ahrens J, Krampfl K, Dengler R and Leuwer M: Endotoxin reduces availability of voltage-gated human skeletal muscle sodium channels at depolarized membrane potentials. Crit Care Med 36: 1239-1247, 2008

64. Guarneri B, Bertolini G and Latronico N: Long-term outcome in patients with critical illness myopathy or neuropathy: The Italian multicentre CRIMYNE study. J Neurol Neurosurg Psychiatry 79: 838-841, 2008.

65. Brealey D, Brand M, Hargreaves I, Heales S, Land J, Smolenski R, Davies NA, Cooper CE and Singer M: Association between mitochondrial dysfunction and severity and outcome of septic shock. Lancet 360: 219-223, 2002.

66. Druschky A, Herkert M, Radespiel-Tröger M, Druschky K, Hund E, Becker CM, Hilz MJ, Erbguth F and Neundörfer B: Critical illness polyneuropathy: Clinical findings and cell culture assay of neurotoxicity assessed by a prospective study. Intensive Care Med 27: 686-693, 2001.

67. Guadarrama-Ortiz P, Choreño-Parra JA, Sánchez-Martínez CM, Pacheco-Sánchez FJ, Rodríguez-Nava AI and García-Quintero G: Neurological aspects of SARS-CoV-2 infection: Mechanisms and manifestations. Front Neurol 11: 1039, 2020.

68. Yang Y, Shen C, Li J, Yuan J, Wei J, Huang F, Wang F, Li G, Li Y, Xing L, et al: Plasma IP-10 and MCP-3 levels are highly associated with disease severity and predict the progression of COVID-19. J Allergy Clin Immunol 146: 119-127.e4, 2020.

69. Chen G, Wu D, Guo W, Cao Y, Huang D, Wang H, Wang T, Zhang $\mathrm{X}$, Chen $\mathrm{H}$, Yu $\mathrm{H}$, et al: Clinical and immunological features of severe and moderate coronavirus disease 2019. J Clin Invest 130: 2620-2629, 2020.

70. Winkelman C: Inactivity and inflammation: Selected cytokines as biologic mediators in muscle dysfunction during critical illness. AACN Clin Issues 15: 74-82, 2004.

71. Maier S, Motataianu A, Barcutean L, Balint A, Hutanu A, Bajko Z, Stoian A, And one S and Balasa R: Interferon- $\beta$ 1A, an immunomodulator in relapsing remitting multiple sclerosis patients. The effect on pro-inflammatory cytokines. Farmacia 68 : 65-75, 2020.

72. Crisafulli S, Isgrò V, La Corte L, Atzeni $\mathrm{F}$ and Trifirò $\mathrm{G}$ : Potential role of anti-interleukin (IL)-6 drugs in the treatment of COVID-19: Rationale, clinical evidence and risks. BioDrugs 34: 415-422, 2020

73. Mehta P, McAuley DF, Brown M, Sanchez E, Tattersall RS and Manson JJ; HLH Across Speciality Collaboration, UK: COVID-19: Consider cytokine storm syndromes and immunosuppression. Lancet 395: 1033-1034, 2020.

74. Van Aerde N, Van den Berghe G, Wilmer A, Gosselink R and Hermans G; COVID-19 Consortium: Intensive care unit acquired muscle weakness in COVID-19 patients. Intensive Care Med 46: 2083-2085, 2020.

75. Tuttle CS, Thang LAN and Maier AB: Markers of inflammation and their association with muscle strength and mass: A systematic review and meta-analysis. Ageing Res Rev 64: 101185, 2020.

76. Morley JE, Kalantar-Zadeh K and Anker SD: COVID-19: A major cause of cachexia and sarcopenia? J Cachexia Sarcopenia Muscle 11: 863-865, 2020.

77. Madia F, Merico B, Primiano G, Cutuli SL, De Pascale G and Servidei S: Acute myopathic quadriplegia in patients with COVID-19 in the intensive care unit. Neurology 95: 492-494, 2020

78. Li YP and Reid MB: NF-kappaB mediates the protein loss induced by TNF-alpha in differentiated skeletal muscle myotubes. Am J Physiol Regul Integr Comp Physiol 279: R1165-R1170, 2000.

79. Li YP, Schwartz RJ, Waddell ID, Holloway BR and Reid MB: Skeletal muscle myocytes undergo protein loss and reactive oxygen-mediated NF-kappaB activation in response to tumor necrosis factor alpha. FASEB J 12: 871-880, 1998.

80. Cooney RN, Maish GO III, Gilpin T, Shumate ML, Lang CH and Vary TC: Mechanism of IL-1 induced inhibition of protein synthesis in skeletal muscle. Shock 11: 235-241, 1999.

81. Shakoory B, Carcillo JA, Chatham WW, Amdur RL, Zhao H, Dinarello CA, Cron RQ and Opal SM: Interleukin-1 receptor blockade is associated with reduced mortality in sepsis patients with features of macrophage activation syndrome: reanalysis of a prior phase III trial. Crit Care Med 44: 275-281, 2016. 
82. Del Valle DM, Kim-Schulze S, Huang HH, Beckmann ND, Nirenberg S, Wang B, Lavin Y, Swartz TH, Madduri D, Stock A, et al: An inflammatory cytokine signature predicts COVID-19 severity and survival. Nat Med 26: 1636-1643, 2020

83. Ruan Q, Yang K, Wang W, Jiang L and Song J: Clinical predictors of mortality due to COVID-19 based on an analysis of data of 150 patients from Wuhan, China. Intensive Care Med 46: 846-848, 2020.

84. Wang J, Zhang H, Qiao R, Ge Q, Zhang S, Zhao Z, Tian C, Ma Q and Shen N: Thrombo-inflammatory features predicting mortality in patients with COVID-19: The FAD-85 score. J Int Med Res 48: 300060520955037, 2020.

85. Chinese Clinical Trial Register (ChiCTR): The World Health Organization International Clinical Trials Registered Organization Registered Platform. Available from: http://www.chictr.org. $\mathrm{cn} /$ showprojen .aspx?proj=49409.

86. Ristimäki A, Narko K and Hla T: Down-regulation of cytokine-induced cyclo-oxygenase- 2 transcript isoforms by dexamethasone: Evidence for post-transcriptional regulation. Biochem J 318: 325-331, 1996.

87. Almawi WY and Melemedjian OK: Negative regulation of nuclear factor-kappaB activation and function by glucocorticoids. J Mol Endocrinol 28: 69-78, 2002.

88. Yang Z, Liu J, Zhou Y, Zhao X, Zhao Q and Liu J: The effect of corticosteroid treatment on patients with coronavirus infection: A systematic review and meta-analysis. J Infect 81: e13-e20, 2020.

89. Gupta A and Gupta Y: Glucocorticoid-induced myopathy: Pathophysiology, diagnosis, and treatment. Indian J Endocrinol Metab 17: 913-916, 2013

90. Wang W, Su B, Pang L, Qiao L, Feng Y, Ouyang Y, Guo X, Shi $\mathrm{H}$, Wei F, Su X, et al: High-dimensional immune profiling by mass cytometry revealed immunosuppression and dysfunction of immunity in COVID-19 patients. Cell Mol Immunol 17: $650-652,2020$

91. Diao B, Wang C, Tan Y, Chen X, Liu Y, Ning L, Chen L, Li M, Liu Y, Wang G, et al: Reduction and functional exhaustion of $\mathrm{T}$ cells in patients with coronavirus disease 2019 (COVID-19). Front Immunol 11: 827, 2020

92. Ono S, Tsujimoto H, Hiraki S and Aosasa S: Mechanisms of sepsis-induced immunosuppression and immunological modification therapies for sepsis. Ann Gastroenterol Surg 2: 351-358, 2018

93. Mao L, Jin H, Wang M, Hu Y, Chen S, He Q, Chang J, Hong C, Zhou Y, Wang D, et al: Neurologic manifestations of hospitalized patients with coronavirus disease 2019 in Wuhan, China. JAMA Neurol 77: 683-690, 2020

94. Yu YM, Ryan CM, Fei ZW, Lu XM, Castillo L, Schultz JT, Tompkins RG and Young VR: Plasma L-5-oxoproline kinetics and whole blood glutathione synthesis rates in severely burned adult humans. Am J Physiol Endocrinol Metab 282: E247-E258, 2002.

95. Beigel JH, Tomashek KM, Dodd LE, Mehta AK, Zingman BS, Kalil AC, Hohmann E, Chu HY, Luetkemeyer A, Kline S, et al: Remdesivir for the treatment of Covid-19-final report. N Engl J Med 383: 1813-1826, 2020.

96. Alattar R, Ibrahim TBH, Shaar SH, Abdalla S, Shukri K, Daghfal JN, Khatib MY, Aboukamar M, Abukhattab M, Alsoub HA, et al: Tocilizumab for the treatment of severe coronavirus disease 2019. J Med Virol 92: 2042-2049, 2020

97. Alvarez JI, Dodelet-Devillers A, Kebir H, Ifergan I, Fabre PJ, Terouz S, Sabbagh M, Wosik K, Bourbonnière L, Bernard M, et al: The Hedgehog pathway promotes blood-brain barrier integrity and CNS immune quiescence. Science 334 $1727-1731,2011$

98. De Luca G, Cavalli G, Campochiaro C, Della-Torre E, Angelillo P, Tomelleri A, Boffini N, Tentori S, Mette F, Farina N, et al: GM-CSF blockade with mavrilimumab in severe COVID-19 pneumonia and systemic hyperinflammation: A single-centre, prospective cohort study. Lancet Rheumatol 2 e465-e 473, 2020

99. Villar J, Ferrando C, Martínez D, Ambrós A, Muñoz T, Soler JA, Aguilar G, Alba F, González-Higueras E, Conesa LA, et al Dexamethasone treatment for the acute respiratory distress syndrome: A multicentre, randomised controlled trial. Lancet Respir Med 8: 267-276, 2020

100. Stoian A, Motătăianu A, Bărcutean L, Maier S, Bazko Z, Voidăzan S, Fărcas A and Bălașa R: Understandig the mechanism of action of intravenous immunoglobulins: A ten years experience in treating Guillain-Barrésyndrome. Farmacia 68 $426-435,2020$.
101. Khanna N, Widmer AF, Decker M, Steffen I, Halter J, Heim D, Weisser M, Gratwohl A, Fluckiger U and Hirsch HH: Respiratory syncytial virus infection in patients with hematological diseases: Single-center study and review of the literature. Clin Infect Dis 46: 402-412, 2008.

102. Wang JT, Sheng WH, Fang CT, Chen YC, Wang JL, Yu CJ, Chang SC and Yang PC: Clinical manifestations, laboratory findings, and treatment outcomes of SARS patients. Emerg Infect Dis 10: 818-824, 2004.

103. Arabi YM, Arifi AA, Balkhy HH, Najm H, Aldawood AS, Ghabashi A, Hawa H, Alothman A, Khaldi A and Al Raiy B: Clinical course and outcomes of critically ill patients with Middle East respiratory syndrome coronavirus infection. Ann Intern Med 160: 389-397, 2014.

104. Brunner R, Rinner W, Haberler C, Kitzberger R, Sycha T, Herkner H, Warszawska J, Madl C and Holzinger U: Early treatment with IgM-enriched intravenous immunoglobulin does not mitigate critical illness polyneuropathy and/or myopathy in patients with multiple organ failure and SIRS/sepsis: A prospective, randomized, placebo-controlled, double-blinded trial. Crit Care 17: R213, 2013.

105. Mohr M, Englisch L, Roth A, Burchardi H and Zielmann S: Effects of early treatment with immunoglobulin on critical illness polyneuropathy following multiple organ failure and gram-negative sepsis. Intensive Care Med 23: 1144-1149, 1997.

106. Koch S, Wollersheim T, Bierbrauer J, Haas K, Mörgeli R, Deja M, Spies CD, Spuler S, Krebs M and Weber-Carstens S: Long-term recovery In critical illness myopathy is complete, contrary to polyneuropathy. Muscle Nerve 50: 431-436, 2014.

107. Latronico $\mathrm{N}$ and Guarneri B: Critical illness myopathy and neuropathy. Minerva Anestesiol 74: 319-323, 2008.

108. Zifko UA: Long-term outcome of critical illness polyneuropathy. Muscle Nerve Suppl 9: S49-S52, 2000.

109. Fletcher SN, Kennedy DD, Ghosh IR, Misra VP, Kiff K, Coakley JH and Hinds CJ: Persistent neuromuscular and neurophysiologic abnormalities in long-term survivors of prolonged critical illness. Crit Care Med 31: 1012-1016, 2003.

110. de Sèze M, Petit H, Wiart L, Cardinaud JP, Gaujard E, Joseph PA, Mazaux JM and Barat M: Critical illness polyneuropathy. A 2-year follow-up study in 19 severe cases. Eur Neurol 43: 61-69, 2000.

111. Kerbaul F, Brousse M, Collart F, Pellissier JF, Planche D, Fernandez C, Gouin F and Guidon C: Combination of histopathological and electromyographic patterns can help to evaluate functional outcome of critical ill patients with neuromuscular weakness syndromes. Crit Care 8: R358-R366, 2004.

112. Herridge MS, Tansey CM, Matté A, Tomlinson G, Diaz-Granados N, Cooper A, Guest CB, Mazer CD, Mehta S, Stewart TE, et al: Functional disability 5 years after acute respiratory distress syndrome. N Engl J Med 364: 1293-1304, 2011

113. McClafferty B, Umer I, Fye G, Kepko D, Kalayanamitra R Shahid Z, Ramgobin D, Cai A, Groff A, Bhandari A, et al: Approach to critical illness myopathy and polyneuropathy in the older SARS-CoV-2 patients. J Clin Neurosci 79: 241-245, 2020.

114. Tsai LK, Hsieh ST, Chao CC, Chen YC, Lin YH, Chang SC and Chang YC: Neuromuscular disorders in severe acute respiratory syndrome. Arch Neurol 61: 1669-1673, 2004.

115. Cao W, Liu X, Bai T, Fan H, Hong K, Song H, Han Y, Lin L, Ruan L and Li T: High-dose intravenous immunoglobulin as a therapeutic option for deteriorating patients with coronavirus disease 2019. Open Forum Infect Dis 7:ofaa102, 2020.

116. Richardson S, Hirsch JS, Narasimhan M, Crawford JM, McGinn T, Davidson KW; the Northwell COVID-19 Research Consortium, Barnaby DP, Becker LB, Chelico JD, Cohen SL, et al: Presenting characteristics, comorbidities, and outcomes among 5700 patients hospitalized with COVID-19 in the New York City Area. JAMA 323: 2052-2059, 2020

117. Chen LYC, Hoiland RL, Stukas S, Wellington CL and Sekhon MS: Confronting the controversy: Interleukin- 6 and the COVID-19 cytokine storm syndrome. Eur Respir J 56: 2003006, 2020.

118. Shimizu M: Clinical Features of Cytokine Storm Syndrome. In: Cytokine Storm Syndrome. Cron RQ and Behrens EM (eds). Springer International Publishing, Cham, pp31-41, 2019.

119. Lucas C, Wong P, Klein J, Castro TBR, Silva J, Sundaram M, Ellingson MK, Mao T, Oh JE, Israelow B, et al: Longitudinal analyses reveal immunological misfiring in severe COVID-19. Nature 584: 463-469, 2020.

120. Blanco-Melo D, Nilsson-Payant BE, Liu WC, Uhl S, Hoagland D, Møller R, Jordan TX, Oishi K, Panis M, Sachs D, et al: Imbalanced host response to SARS-CoV-2 drives development of COVID-19. Cell 181: 1036-1045.e.9, 2020 
121. Chen LYC, Hayden A and Mattman A: Extreme hyperferritinaemia, soluble interleukin-2 receptor, and haemophagocytic lymphohistiocytosis. Br J Haematol 185: 605-606, 2019.

122. Giamarellos-Bourboulis EJ, Netea MG, Rovina $\mathrm{N}$, Akinosoglou K, Antoniadou A, Antonakos N, Damoraki G, Gkavogianni T, Adami ME, Katsaounou P, et al: Complex immune dysregulation in COVID-19 patients with severe respiratory failure. Cell Host Microbe 27: 992-1000.e3, 2020.

123. Mazzoni A, Salvati L, Maggi L, Capone M, Vanni A, Spinicci M Mencarini J, Caporale R, Peruzzi B, Antonelli A, et al: Impaired immune cell cytotoxicity in severe COVID-19 is IL-6 dependent. J Clin Invest 130: 4694-4703, 2020.

124. RECOVERY Collaborative Group; Horby P, Lim WS, Emberson JR, Mafham M, Bell JL, Linsell L, Staplin N, Brightling C,Ustianowski A, et al: Dexamethasone in Hospitalized Patients with Covid-19. N Engl J Med 384: 693-704, 2021.

125. San-Juan D, Jiménez CR, Camilli CX, de la Cruz Reyes LA, Galindo EG, Burbano GE, Penela MM, Perassolo MB, Valdéz AT, Godoy JG, et al: Guidance for clinical neurophysiology examination throughout the COVID-19 pandemic. Latin American chapter of the IFCN task force-COVID-19. Clin Neurophysiol 131: 1589-1598, 2020.

126. Fan E, Cheek F, Chlan L, Gosselink R, Hart N, Herridge MS, Hopkins RO, Hough CL, Kress JP, Latronico N, et al: An official American Thoracic Society Clinical Practice guideline: The diagnosis of intensive care unit-acquired weakness in adults. Am J Respir Crit Care Med 190: 1437-1446, 2014.

127. Batt J, dos Santos CC, Cameron JI and Herridge MS: Intensive care unit-acquired weakness: Clinical phenotypes and molecular mechanisms. Am J Respir Crit Care Med 187: 238-246, 2013.

128. Z'Graggen WJ and Tankisi H: Critical illness myopathy. J Clin Neurophysiol 37: 200-204, 2020.

129. Stoian A, Serban G, Bajko Z, And one S, Mosora O and Bălașa A: Therapeutic plasma exchange as a first-choice therapy for axonal Guillain-Barré syndrome: A case-based review of the literature (Review). Exp Ther Med 21: 265, 2021.

130. Barreiro E: Models of disuse muscle atrophy: Therapeutic implications in critically ill patients. Ann Transl Med 6: 29, 2018

131. Batt J, Herridge M and Dos Santos C: Mechanism of ICUacquired weakness: Skeletal muscle loss in critical illness. Intensive Care Med 43: 1844-1846, 2017.

132. Parotto M, Batt J and Herridge M: The pathophysiology of neuromuscular dysfunction in critical illness. Crit Care Clin 34 549-556, 2018

133. Stoian A, Motățăianu A, Bajko Z and Bălașa A: Guillain-barré and acute transverse myelitis overlap syndrome following obstetric surgery. J Crit Care Med (Targu Mures) 6: 74-79, 2020

134. Burch PM, Pogoryelova O, Goldstein R, Bennett D, Guglieri M, Straub V, Bushby K, Lochmüller H and Morris C: Muscle-derived proteins as serum biomarkers for monitoring disease progression in three forms of muscular dystrophy. J Neuromuscul Dis 2: $241-255,2015$

135. Baird MF, Graham SM, Baker JS and Bickerstaff GF: Creatinekinase- and exercise-related muscle damage implications for muscle performance and recovery. J Nutr Metab 2012: 960363, 2012.

136. Kim EY, Lee JW, Suh MR, Choi WA, Kang SW and Oh HJ: Correlation of serum creatine kinase level with pulmonary function in Duchenne muscular dystrophy. Ann Rehabil Med 41: 306-312, 2017

137. Tabarsi P, Barati S, Jamaati H, Haseli S, Marjani M, Moniri A, Abtahian Z, Dastan A, Yousefian S, Eskandari R, et al: Evaluating the effects of Intravenous Immunoglobulin (IVIg) on the management of severe COVID-19 cases: A randomized controlled trial. Int Immunopharmacol 90: 107205, 2021.
138. Jain A, Deval N and Paul L: A recovered case of COVID-19 myocarditis treated with IV immunoglobulin. Chest 158: A281, 2020.

139. Galeotti C, Kaveri SV and Bayry J: IVIG-mediated effector functions in autoimmune and inflammatory diseases. Int Immunol 29: 491-498, 2017.

140. Hartung HP: Advances in the understanding of the mechanism of action of IVIg. J Neurol 255 (Suppl 3): 3-6, 2008

141. Lai ST: Treatment of severe acute respiratory syndrome. Eur J Clin Microbiol Infect Dis 24: 583-591, 2005.

142. Balasa R: Therapeutic plasma exchange: An indispensable therapy for severe neurological condition. J Crit Care Med (Targu Mures) 6: 89-90, 2020.

143. Hung IFN, To KKW, Lee CK, Lee KL, Yan WW, Chan K, Chan WM, Ngai CW, Law KI, Chow FL, et al: Hyperimmune IV immunoglobulin treatment: A multicenter double-blind randomized controlled trial for patients with severe 2009 influenza A(H1N1) infection. Chest 144: 464-473, 2013.

144. Nguyen AA, Habiballah SB, Platt CD, Geha RS, Chou JS and McDonald DR: Immunoglobulins in the treatment of COVID-19 infection: Proceed with caution! Clin Immunol 216: 108459, 2020.

145. Xie Y, Cao S, Dong H, Li Q, Chen E, Zhang W, Yang L, Fu S and Wang R: Effect of regular intravenous immunoglobulin therapy on prognosis of severe pneumonia in patients with COVID-19. J Infect 81: 318-356, 2020

146. Reynaga E, Carrillo J, Santos JR, Roure S, Mateu L, Paredes R, Clotet B, Izquierdo-Useros N and Pedro-Botet ML: Outcome of hospitalized patients with COVID-19 pneumonia treated with high-dose immunoglobulin therapy in a prospective case series. Clin Microbiol Infect 27: 651-652, 2021.

147. Busani S, Damiani E, Cavazzuti I, Donati A and Girardis M: Intravenous immunoglobulin in septic shock: Review of the mechanisms of action and meta-analysis of the clinical effectiveness. Minerva Anestesiol 82: 559-572, 2016.

148. Schwab I and Nimmerjahn F: Intravenous immunoglobulin therapy: How does IgG modulate the immune system? Nat Rey Immunol 13: 176-189, 2013.

149. Davey RT Jr, Fernández-Cruz E, Markowitz N, Pett S, Babiker AG, Wentworth D, Khurana S, Engen N, Gordin F, Jain MK, et al: Anti-influenza hyperimmune intravenous immunoglobulin for adults with influenza A or B infection (FLU-IVIG): A double-blind, randomised, placebo-controlled trial. Lancet Respir Med 7: 951-963, 2019.

150. Docea AO, Tsatsakis A, Albulescu D, Cristea O, Zlatian O, Vinceti M, Moschos SA, Tsoukalas D, Goumenou M, Drakoulis N, et al: A new threat from an old enemy: Re-emergence of coronavirus (Review). Int J Mol Med 45: 1631-1643, 2020.

151. Calina D, Docea AO,Petrakis D, Egorov AM,Ishmukhametov AA, Gabibov AG, Shtilman MI, Kostoff R, Carvalho F, Vinceti M, et al: Towards effective COVID-19 vaccines: Updates, perspectives and challenges (Review). Int J Mol Med 46: 3-16, 2020.

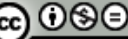

This work is licensed under a Creative Commons Attribution-NonCommercial-NoDerivatives 4.0 International (CC BY-NC-ND 4.0) License. 